\title{
Confidence in expressing novel textures - an analysis of Japanese ideophones that describe visually-induced textures
}

Book or Report Section

Accepted Version

Uno, R., Hirata-Mogi, S., Ogai, Y. and Hayashi, Y. (2017) Confidence in expressing novel textures - an analysis of Japanese ideophones that describe visually-induced textures. In: Proceedings of IEEE International Conference in Cybernetics 2017. IEEE Xplore Digital Library. ISBN 9781538622018 doi:

https://doi.org/10.1109/CYBConf.2017.7985768 Available at http://centaur.reading.ac.uk/70685/

It is advisable to refer to the publisher's version if you intend to cite from the work. See Guidance on citing.

To link to this article DOI: http://dx.doi.org/10.1109/CYBConf.2017.7985768

Publisher: IEEE Xplore Digital Library 
including copyright law. Copyright and IPR is retained by the creators or other copyright holders. Terms and conditions for use of this material are defined in the End User Agreement.

\section{www.reading.ac.uk/centaur}

\section{CentAUR}

Central Archive at the University of Reading

Reading's research outputs online 


\section{Confidence in Expressing Novel Textures}

\section{An Analysis of Japanese Ideophones that Describe Visually-induced Textures}

\author{
Ryoko Uno \\ Division of Language and Culture Sciences, \\ Institute of Engineering, \\ Tokyo University of Agriculture and Technology, \\ Tokyo, Japan. \\ ryokouno@cc.tuat.ac.jp \\ Yuta Ogai \\ Department of Electronics and Mechatronics, \\ Faculty of Engineering, \\ Tokyo Polytechnic University \\ Tokyo, Japan \\ ogai@em.t-kougei.ac.jp
}

\author{
Sachiko Hirata-Mogi \\ IdeaLab Inc., \\ Tokyo, Japan. \\ marshmallow1214@gmail.com
}

\author{
Yoshikatsu Hayashi \\ Biomedical Engineering, \\ School of Biological Sciences, \\ University of Reading, \\ Reading, UK. \\ y.hayashi@reading.ac.uk
}

\begin{abstract}
Although a close relationship between the emergence of a new expression and that of either a new object or concept is presupposed in linguistic analysis, the correlation has not been pursued thoroughly. This paper investigates how people respond to different novel textures within language. We carried out an experiment using an application that displays visually-induced texture. Participants were presented with two types of novel texture: one had a time delay between touching and the texture's response to this and the other did not. Participants were asked to describe the texture with ideophones (sound symbolic words) in Japanese. We observed what kinds of ideophones were used and the confidence with which they were expressed, which produced two results. First, there was a significant difference between the two texture types regarding confidence. For the texture with a delay, active touch was required for subjects to express it with a high level of confidence. Second, when the expressions were made with high confidence, the texture with a delay was expressed with significantly more unconventional ideophones than that without delay.
\end{abstract}

Keywords—novel texture; Japanese ideophones; confidence; unconventional usage; time delay

\section{INTRODUCTION: NEW REALITY, NEW WORDS}

Why do people use new words instead of conventional ones? In the linguistic study of neologism, it is often presupposed that the appearance of either new objects or new concepts is correlated to the emergence of new expressions (for other reasons for the emergence of new words, such as playfulness, see [3], [16], and [17]). For examples, it is pointed out that by having the new word potscaping (which refers to an artistic way to display container gardening), people gained a new concept of container gardening [13]. However, the precise correlation between novel items and new expressions has not been fully studied. In this paper, we try to build a method to determine how novel textures influence linguistic behavior. We asked participants whose native language is Japanese to express virtual textures with different properties by using ideophones (i.e., sound symbolic words). One had a time delay in response compared to the basic condition and the other did not. Our hypothesis was that since the time delay can suggest animacy, which has a high cognitive salience for us, the texture with the time delay must be described with more unconventional ideophones with confidence. Our results showed that the hypothesis was plausible. To begin with, there was a significant difference in confidence levels when expressing the two textures. In addition, the texture with the time delay had significantly more non-conventional ideophones when they are expressed with high confidence. This study proposes a method to predict how virtual reality can affect the mental lexicon.

\section{BACKGROUND}

\section{A. Texture that implies animacy}

We do not necessarily create a new expression whenever a new texture appears. We can often find a similarity between a novel texture and something we already know and count them as members of the same category. We can talk about a new texture with a preexisting expression.

So, when do we decide to make a new expression for a new texture? One possible answer to this question is when the new texture has a property with high cognitive salience; Schmid [14] points out that this can easily lead to the entrenchment of a new linguistic unit.

Among the properties with high cognitive salience, we focus on animacy in this paper. We hypothesize that a texture that implies animacy can easily find new expressions.

As an instance of a texture that hints at animacy, we adopted a virtual texture with a time delay between touching 
by the subject and the response of the texture, taking recent research on time delays into consideration. Following Weiskrantz et al.'s classical study [20], there have been many observations that the ownership of one's own touch can be lost to some extent by loosening sensorimotor coordination. For example, Blanke et al. [2] conducted an experiment using a tool that can be used to poke oneself. The results show that when there is a time lag between the action of poking and the sensation of being poked, the subject feels a "sense of a presence." That is, people may feel that an animate being is present when there is a delayed sensation from a movement made by themselves.

In brief, we suppose that a time delay can be used to suggest animacy and so compared the texture with and without time delay. Both are novel textures in the sense that they are displayed visually. However, we hypothesize that there is a difference in the potential to lead the subjects to produce new expressions.

\section{B. Confidence in expressing textures}

In this research, we consider the case wherein people start making new categories, rather than utilizing preexisting categories, by analyzing newly created expressions. This means that we have to exclude the case where people use unconventional expressions when they cannot categorize because of a lack of information. For this purpose, in the experiment we asked how confident the subjects were in their expressions. We assume that when a subject uses an unconventional expression with high confidence they are making a new category.

\section{Ideophones and virtual objects}

Ideophones, which are also known as mimetics, are sound symbolic expressions that can vividly describe physical experiences [7]. In this experiment, all participants were native speakers of Japanese, which is known to have many ideophones.

The reason we used ideophones in our experiment is twofold. First, ideophones are known to express bodily sensations [8]. Second, it is easy to produce nonce expressions with ideophones [1].

Following the first reason above, there have been numerous attempts to explore the cognition of objects by analyzing how people express those objects using ideophones. For example, in the case of rice crackers [19], baribari is used for the hardest version, paripari for the middle, and mochimochi for the softest.

Some research has also analyzed how people describe virtual objects and movements with ideophones. There are two primary groups of researchers engaged in this. The first uses virtual objects and movements because they are more controllable than real ones. Members of this group work mainly in the fields of robotics and artificial life. For example, Ogai et al. [10] [11] constructed a system that can display artificial tactile sensations. It is an active tactile system that employs a tactile display and a three- dimensional position sensor. With this system, subjects can reconstruct their sensations by mapping them to a certain ideophone. Moreover, subjects can experience sensations created by others. In the experiment, subjects were asked to reconstruct the sensation of zarazara (rough) and uneune (wavy) textures. Another example is a study conducted by Sugiyama and Kondo [15], who used a gait simulator and asked their subjects to reconstruct the movement expressed by using ideopohones.

The second group includes engineering researchers who aim to enhance the quality of artificial textures. For example, Sakamoto et al. [12] compared how real and artificial metals are expressed in ideophones to determine the differences in perception.

Both groups mainly use virtual textures or movements to mimic the real world. In our research, we used virtual textures since they are, at least to some, extent novel to humans. Therefore, the focus in the experiment was on the second reason for utilizing ideophones (i.e., the production of nonce words).

\section{EXPERIMENT}

To ascertain how people linguistically react to novel textures, we developed a visually-induced application that displays virtual textures. In the experiment, we presented various virtual textures to subjects using three methods. We asked the subjects to answer with the ideophone that best expressed each texture and then deduced their confidence in their answer.

\section{A. Application}

It is known that humans can obtain textural information visually [4]. To produce a tactile sensation with visual information, we developed the haptic software platform Evono [9] and its modified version Evono.auto [18] using an iPad 4 (Apple, U.S.) as a hardware platform. The characteristic properties of virtual objects were represented by a visco-elastic property, and the interactive interface with participants was developed by incorporating the trajectory of the fingertip detected on the touch screen. This type of virtual object will be referred to as a "visually-induced texture" in this paper. Figure 1 shows how the subject touches the visually-induced texture using Evono.auto.

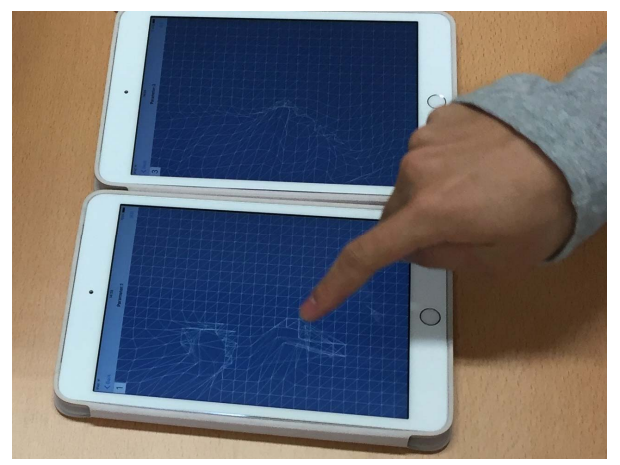

Figure 1. Touching the texture displayed by Evono.auto. 
Two-dimensional beads and a spring-damper model were employed to simulate the dynamics of the virtual objects with different physical properties. Individual beads were placed in the square lattice and connected by a springdamper in a parallel configuration via the shortest distance. Therefore, the dynamics of the two-dimensional network were determined by the mass of the beads $m$, the elastic coefficient of the spring $K$, and the coefficient of viscosity $D$.

Interactions between the virtual object and the motion of the fingertip were realized as follows: 1) We detected the four beads touched by the fingertip, 2) translated the four beads simultaneously with the trajectory of the fingertip, and 3) updated the positions of other beads in the twodimensional network by solving Newton's equation for the spring-mass-damper model, as follows:

$$
m \ddot{x}_{i}=-\sum_{j=1}^{4} K\left(x_{j}-x_{i}-l_{0}\right)-D \dot{x}_{i}
$$

where $x_{i}$ is a position of the $i^{\text {th }}$ bead, and index $j$ runs over the four nearest neighbors.

In addition to the three parameters (the mass of the beads, the elastic coefficient of the spring, and the coefficient of viscosity), a frame delay parameter was introduced. By using this parameter, a texture that reflects the movement with a time delay can be displayed.

\section{B. Method}

Six males and four females aged 20-26 years participated in our experiments. During the trial, participants were seated in a comfortable chair. The texture was presented to the subjects via the following three methods:

\section{1) Static display: showing the participants three} screenshots from the movie clip in 2.

2) Passive dynamic display: showing the participants a video clip of the texture touched by the pointer controlled by someone else.

3) Active dynamic display: allowing participants to touch the texture by themselves

Figure 2 shows three screenshots that reflect the static display method. The texture was presented in the order of static, passive dynamic, and active dynamic methods to increase the information of each texture as the experiment proceeded.
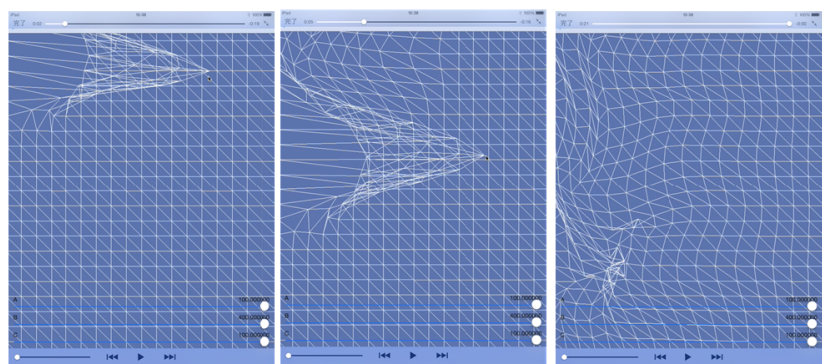

Figure 2. Static display of the texture.
The following six textures, which we grouped into two major types, were presented to the participants:

a) Physical texture: The basic texture and textures based on modifications of its physical properties.

P0: Basic texture.

$P 1: P 0$ with less elasticity.

$P 2$ : $P 0$ with less viscosity.

P3: P0 with less mass.

b) Temporal texture: Textures based on modifications of the temporal properties of the basic texture.

T1: P0 with a 0.25 second time delay.

T2: P0 with a 0.5 second time delay.

After each trial, participants were asked to complete a form with the ideophone that best described the textural sensation. A list of 99 random ideophones were shown to the participants to help explain the notion of an ideophone. All the ideophones in the list had conventional forms. Some of them were the ones used to express tactile sensations while others were not. We told the subjects to use the list as a reference to understand what an ideophone is, but they should not necessarily use an ideophone in the list as an answer. We also told them that they can make up an unconventional ideophone if they wish.

For each ideophone given as an answer, they were asked to rate their confidence in their answer using the following rating system:

\section{Not confident at all. \\ 2 Between 1 and 3. \\ 3 Somewhat confident. \\ 4 Between 3 and 5. \\ 5 Very confident.}

\section{RESULTS AND ANALYSIS}

Based on the categorization of the ideophones provided in the answers, the confidence rates and the occurrence of unconventional ideophones were analyzed specifically to contrast the nature of both physical and temporal textures.

\section{A. Categorization of ideophones}

First, we categorized the answers. Ten participants expressed six textures each, which were presented in three different ways. Thus, 180 tokens of ideophones were given as answers. Among the 180 answers, 82 were on the ideophone list given to the participants.

The 180 tokens were then subcategorized as either conventional or unconventional usage as seen in Table 1. 
Table 1. Categorization of Ideophones.

\begin{tabular}{|l|l|c|}
\hline \multicolumn{2}{|c|}{ Types of Ideophones } & Tokens \\
\hline \multirow{3}{*}{$\begin{array}{l}\text { Conventional } \\
\text { usage }\end{array}$} & (a) Physical property & 44 \\
\cline { 2 - 3 } & (b) Movement & 27 \\
\cline { 2 - 3 } & (c) Feelings & 2 \\
\hline \multirow{2}{*}{$\begin{array}{l}\text { Unconventional } \\
\text { usage }\end{array}$} & (d) Unconventional meaning & 67 \\
\cline { 2 - 3 } & (e) Unconventional form & 40 \\
\hline
\end{tabular}

There are three subtypes in conventional usage. An ideophone expresses a physical property (e.g., nebaneba for "sticky"), motion (e.g., $s a$ for "quickly"), and the inner state of a person, the subject touching the texture in this case (e.g., iraira for "being irritated"). These ideophones are used in conventional ways as defined in the dictionary. In contrast, unconventional usage means that the ideophones are either used differently than their dictionary definition or they are not listed at all. For example, although nobinobi usually expresses a relaxed feeling, it was used to describe the texture in this answer irrespective of the conventional meaning. Some of the answers, such as kyoon or nton, were created by the participants. Among the answers 59\% of them were unconventional usages.

Due to space constraints, only answers for textures P1 and $\mathrm{T} 1$ are given in Table 2 as samples.

Table 2. Ideophones for P1 and T1.

\begin{tabular}{|c|c|c|c|}
\hline \multirow[t]{2}{*}{ Texture } & \multirow[t]{2}{*}{ Display } & \multicolumn{2}{|c|}{ Ideophones (types) } \\
\hline & & Conventional & Unconventional \\
\hline \multirow[t]{3}{*}{$\begin{array}{l}\text { Physical } \\
\text { P1 }\end{array}$} & Static & $\begin{array}{l}\text { gotsugotsu }(\mathrm{a}), \\
\text { baribari }(\mathrm{a}) .\end{array}$ & $\begin{array}{l}\text { karikari }(\mathrm{d}), \text { shakiin }(\mathrm{d}), \\
\text { bakoon }(\mathrm{e}), \text { gui }(\mathrm{d}), \\
\text { waa }(\mathrm{d}), \text { gatsugastu }(\mathrm{d}), \\
\text { gishigishi }(\mathrm{d}), \text { kyoon }(\mathrm{e}) .\end{array}$ \\
\hline & $\begin{array}{l}\text { Passive } \\
\text { dynamic }\end{array}$ & $\begin{array}{l}\text { hyoi }(\mathrm{b}) \\
\text { biyoon }(\mathrm{b}) \\
\text { nebaneba }(\mathrm{a}) \\
\text { hyoi }(\mathrm{b})\end{array}$ & $\begin{array}{l}\text { nechinechi }(\mathrm{d}), \\
\text { shikoshiko }(\mathrm{d}), \text { gui }(\mathrm{d}), \\
\text { guigui }(\mathrm{d}), \operatorname{dosshiri}(\mathrm{d}), \\
\text { kyoon }(\mathrm{e}) .\end{array}$ \\
\hline & $\begin{array}{l}\text { Active } \\
\text { dynamic }\end{array}$ & $\begin{array}{l}\text { hyoi }(\mathrm{b}) \\
\text { nebaneba }(\mathrm{a}), \\
\text { sarasara }(\mathrm{a}), \\
\text { nebaneba }(\mathrm{a}) \\
\text { nurunuru }(\mathrm{a}) \\
\text { hyoi }(\mathrm{b}) \\
\end{array}$ & $\begin{array}{c}\text { nayonayo }(\mathrm{d}), \text { suko }(\mathrm{e}), \\
\text { kyoon }(\mathrm{e}) .\end{array}$ \\
\hline \multirow[t]{3}{*}{$\begin{array}{c}\text { Temporal } \\
\text { T1 }\end{array}$} & Static & $\begin{array}{c}\text { petapeta }(\mathrm{a}), \\
\operatorname{doro}(\mathrm{a}) .\end{array}$ & $\begin{array}{c}\text { shan }(\mathrm{d}), \text { ton }(\mathrm{d}), \\
\text { bakoon }(\mathrm{e}), \\
\text { kuchakucha }(\mathrm{d}), \\
\text { mozomozo }(\mathrm{d}), \\
\text { don }(\mathrm{d}), \text { gotegote }(\mathrm{d}), \text { kyuun } \\
(\mathrm{e}) .\end{array}$ \\
\hline & $\begin{array}{l}\text { Passive } \\
\text { dynamic }\end{array}$ & $\begin{array}{l}\text { sowasowa }(\mathrm{c}), \\
\text { neto }(\mathrm{a}) \\
\text {, fuwafuwa (a), } \\
\text { petapeta }(\mathrm{a}), \text { sa } \\
\text { (b). }\end{array}$ & $\begin{array}{c}\text { motamota }(\mathrm{d}), \text { tooon }(\mathrm{e}), \\
\text { bakoon }(\mathrm{e}), \text { don }(\mathrm{d}), \\
\text { kyuun }(\mathrm{e}) .\end{array}$ \\
\hline & $\begin{array}{c}\text { Active } \\
\text { dynamic }\end{array}$ & neto (a), sa (b). & $\begin{array}{c}\text { shan }(\mathrm{d}), \operatorname{motamota}(\mathrm{d}), \text { nton } \\
(\mathrm{e}), \operatorname{don}(\mathrm{d}), \\
\text { saa }(\mathrm{d}), \operatorname{nobinobi}(\mathrm{d}), \\
\operatorname{don}(\mathrm{d}), \text { ukyuun }(\mathrm{e}) .\end{array}$ \\
\hline
\end{tabular}

\section{B. Confidence rate}

Next, we contrasted physical and temporal textures in terms of confidence rate. Figure 3 shows the average confidence rate for physical textures (P0, P1, P2, and P3) and temporal textures (T1 and $\mathrm{T} 2$ ).

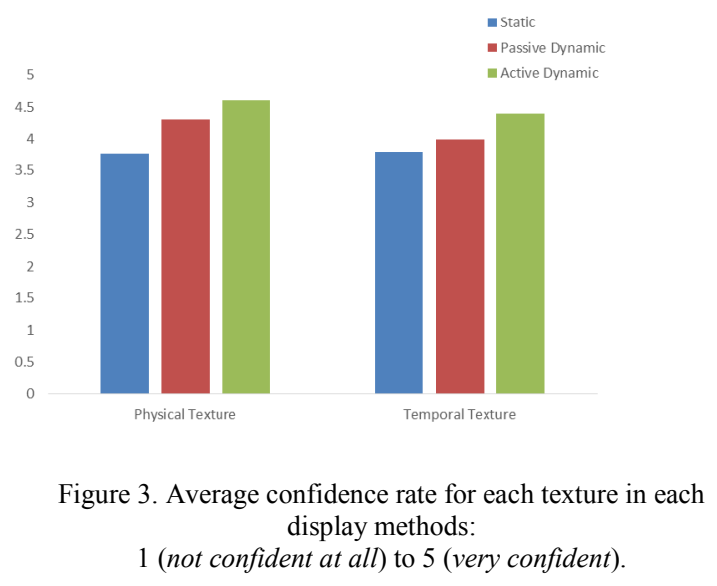

To investigate if the certainty value depends on the display method and/or changes in texture, we performed an ANOVA for the three display methods and the two texture conditions. Thus, while the main effect of the display methods showed significance $(\mathrm{F}[2 / 18]=15.410, \mathrm{p}<$ $0.001)$, the texture condition did not show significance for the main effect $(\mathrm{F}[1 / 9]=2.687, \mathrm{p}=1.600)$ and interaction $(\mathrm{F}[2 / 16]=1.780, \mathrm{p}=0.200)$.

As the main effect of the display method showed significance, we performed multiple comparisons using the Ryan method and found differences in 1) static and passive dynamic, 2) static and active dynamic, and 3) passive dynamic and active dynamic $(\mathrm{p}<0.050)$.

In summary, we can confirm that the confidence rate decreases in the order of static, passive dynamic, and active dynamic display conditions.

In each condition, the simple main effect of the display methods demonstrated the statistical significance of the physical texture condition $(\mathrm{F}[2 / 36]=14.281, \mathrm{p}<0.001)$ and the temporal texture condition $(\mathrm{F}[2 / 36]=4.509, \mathrm{p}<$ 0.005). As a next step, we applied multiple comparisons using the Ryan method. The results showed that there is a significant difference 1) in the physical texture condition between static and active dynamic and between static and passive dynamic and 2) in the temporal texture condition between static and active dynamic and between passive dynamic and active dynamic $(\mathrm{p}<0.050)$.

\section{Unconventional usages}

Finally, we checked the frequency of unconventional usages. In the case of physical textures (P0, P1, P2, and P3), the ratio of unconventional usage increased in the static display condition, but decreased in the passive dynamic and active dynamic conditions as shown in Table 3 . However, in the case of temporal textures ( $\mathrm{T} 1$ and $\mathrm{T} 2$ ), the ratio of unconventional usage is always high as shown in Table 4. 
Following the previous section investigating the confidence rate, we investigated if the ratio of unconventional usage was dependent on the texture conditions (physical and temporal).

Table 3. Frequency of unconventional usage (physical texture condition) in each display method.

\begin{tabular}{|c|c|c|}
\hline & Conventional & Unconventional \\
\hline Static & 13 & 27 \\
\hline $\begin{array}{c}\text { Passive } \\
\text { dynamic }\end{array}$ & 19 & 21 \\
\hline $\begin{array}{c}\text { Active } \\
\text { dynamic }\end{array}$ & 23 & 17 \\
\hline
\end{tabular}

Table 4. Frequency of unconventional usage (temporal texture condition) in each display method.

\begin{tabular}{|c|c|c|}
\hline & Conventional & Unconventional \\
\hline Static & 6 & 14 \\
\hline $\begin{array}{c}\text { Passive } \\
\text { dynamic }\end{array}$ & 8 & 12 \\
\hline $\begin{array}{c}\text { Active } \\
\text { dynamic }\end{array}$ & 4 & 16 \\
\hline
\end{tabular}

In order to directly test our hypothesis in Section I, we performed the statistical tests with a focus on the active dynamic display method, which generated higher confidence rates (as we noted in Section II B, to see the occurrence of new categories with new ideophones, unconventional usage with low confidence must be excluded). An $\mathrm{X}$ squared test was performed to find the correlation between the frequency of conventional and unconventional usage as shown in Tables 3 and 4 . We found the statistical significance in their correlations $(\chi 2=8.01, \mathrm{df}$ $=1, \mathrm{p}<0.010, \mathrm{~V}=0.36)$. Further, residual analysis showed that the temporal texture condition could induce a higher frequency of unconventional usage than conventional usage ( $\mathrm{p}<0.010)$, thus concluding that our hypothesis was plausible.

\section{DISCUSSION AND CONCLUSION}

Both textures - physical and temporal-were novel to the participants in the sense that they were virtual. However, there was an assumed difference in cognitive salience. Our hypothesis was that since the temporal texture can imply animacy, it becomes more salient than the physical texture and thus the temporal texture might be expressed with more unconventional usage with high confidence than the physical texture.

The results obtained from the ideophone data showed that almost $59 \%$ of the visually-induced textures were expressed with the unconventional usages of ideophones. In our former analysis [19], we asked 85 participants to express the texture of seven types of rice cracker. For each cracker, at least one or two ideophones occurred more than $10 \%$ of the time in the participants' first answers. Of course, all were conventional ideophones. While the experimental structure was different, we can see that, for virtual textures in general, there is less overlap in the choice of ideophones, which may lead to more unconventional usages. We assume that novel textures in general can potentially generate more novel expressions than normal textures.

Turning to the confidence rate, we can see that the method of presentation and both types of texture affect confidence in expressing texture. In the case of physical texture, the more information available about the texture, the greater the confidence in expressing it. In contrast, in expressing the temporal texture, passive dynamic presentation did not increase confidence, while active dynamic presentation did. For temporal texture to be expressed linguistically with confidence, active touchfrom Gibson's classical experiment [6]—was required.

Lastly, we observed the frequency of the unconventional usage of ideophones with respect to confidence rate. We found that, when expressed with confidence, the frequency of unconventional ideophones is significantly higher for temporal textures than for physical textures. This result is consistent with our hypothesis.

To see whether this result truly relies on the time delay's implication of animacy, we are planning to test a texture that responds randomly to touch. It might also be useful to test properties other than time delay that hint at animacy by referring to the other studies that explore the relationship between time and animacy or agency using virtual reality experiments (e.g., [5]).

This paper reflects only on the first step in revealing the correlation between novel textures and new words. Our aim is to extend this research based on the method used in this paper and to explore the role played by novelty in language changes.

\section{ACKNOWLEDGEMENTS}

We thank Keisuke Suzuki for useful comments. This work is supported by JSPS KAKENHI Grant Number 15K00199.

\section{REFERENCES}

[1] K. Akita, "Toward a frame-semantic definition of sound-symbolic words," Cognitive Linguistics, vol. 23, pp.67-90, 2012.

[2] O. Blanke, P. Pozeg, M. Hara, L. Heydrich, A. Serino, A. Yamamoto, T. Higuchi, R. Salomon, M. Seeck, T. Landis, S. Arzy, B. Herbelin, H. Bleuler and G. Rognini, "Neurological and robotcontrolled induction of an apparition," Current Biology. vol. 24, no. 22, pp. 2681-2686, 2014.

[3] D. Crystal, "Language Play," Harmondsworth: Penguin, 1998.

[4] J.R. Flanagan and J.L. Susan, "Feeling bumps and holes," Nature, vol. 412, pp. 389-391, 2001.

[5] T. Froese, H. Iizuka, and T. Ikegami, "Embodied social interaction constitutes social cognition in pairs of humans: A minimalist virtual reality experiment," Scientific Reports 4, Article number: 3672, 2014.

[6] J.J. Gibson, "Observations on active touch," Psychological Review, vol. 69 , no. 6 , pp. $477-491,1962$. 
[7] S. Hamano, "The sound-symbolic system of Japanese," Stanford: CSLI Publications, 1998.

[8] S. Kita, "Two-dimensional semantic analysis of Japanese mimetics," Linguistics, vol. 35, pp.379-415, 1997.

[9] Y. Ogai, "Development and use of iOS application that diplays textures expressed with mimetics," Cross-Sectional Studies in Comparative Culture, Tokyo: Kaibunsya, pp.140-153, 2016. (in Japanese)

[10] Y. Ogai and T. Ikegami, "An investigation of active touch using neural networks and a tactile display constructing tactile sensations represented by onomatopoeias," IEICE Technical Report, vol. 109, no. 83, pp.17-21, 2009. (in Japanese)

[11] Y. Ogai, R. Uno, and T. Ikegami, "From active perception to language analysis of onomatopoeias using a tactile display," Handbook of the 3rd International Symposium on Mobiligence, pp.382-386, 2009.

[12] M. Sakamoto, J. Yoshino, R. Doizaki, and M. Haginoya, "Metal-like texture design evaluation using sound symbolic words, " International Journal of Design Creativity and Innovation, DOI: 10.1080/21650349.2015.1061449, 2015.

[13] H.J. Schmid, "New words in the mind: Cocept-formation and entrenchment of neologisms," Anglia, vol. 126, pp.1-36, 2008.

[14] H.J. Schmid, "Entrenchment, salience, and basic levels," D. Geeraerts and H. Cuyckens eds., The Oxford Handbook of Cognitive Linguistics, 117-138, 2016.

[15] Y. Sugiyama and T. Kondo, "A constructive approach to the understanding of emotion and onomatopoeia through behavior design of walking robot," the $20^{\text {th }}$ Fuzzy, Artificial Intelligence, Neural Networks and Computational Intelligence Symposium, 2010. (In Japanese)

[16] N. Tsujimura and D. Stuart, "A construction approach to innovative verbs in Japanese," Cognitive Linguistics, vol. 22, pp.797-823, 2011.

[17] R. Uno, N. Kaji, M. Kitsuregawa, "Exploring form/meaning interaction through analysis of a neologism," the $12^{\text {th }}$ International Cognitive Linguistics Conference, 2013.

[18] R. Uno, Y. Hayashi, and Y.Ogai, "Mimetic expressions as a tool to measure awareness of causation," Sound Symbolism Workshop, 2013.

[19] R. Uno, F. Kobayashi, K. Shinohara, and S. Odake, "The mimetic expressions for rice crackers," UK-Cognitive Linguistics Conference, 2016.

[20] L. Weiskrantz, J. Elliott \& C. Darlington, "Preliminary observations on tickling oneself," Nature, vol.230, pp. 598-599, 1971. 